\title{
New cassettes for single-step drug-resistance and prototrophic marker switching in fission yeast
}

\author{
Alexander Lorenz \\ Institute of Medic al Sc iences, University of Aberdeen, Foresterhill, Aberdeen AB25 2ד, UK \\ Correspondence to Alexander Lorenz (Phone: +441224 437323, Fax: +441224 437506, e-mail: a.lorenz@abdn.ac.uk)
}

Yeast (2015) 32: 703-710

This is the peer-reviewed version of the following article: Lorenz A (2015) New cassettes for single-step drug-resistance and prototrophic marker switching in fission yeast. - Yeast 32 (12): 703-710, which has been published in final form at [http://dx.doi.org/10.1002/yea.3097]. This article may be used for non-commercial purposes in accordance with Wiley Terms and Conditions for Self-Archiving.

\begin{abstract}
Construction of multiply mutated strains for genetic interaction analysis and of strains carrying different epitope tags at multiple open reading frames for testing protein localization, abundance and protein-protein interactions is hampered by the availability of a sufficient number of different selectable markers. Moreover, strains with single gene deletions or tags often already exist in strain collections; for historical reasons these will mostly carry the $\mathrm{ura}^{+}$gene or the G418resistance kanMX as marker. Because it is rather cumbersome to produce multiply deleted or tagged strains using the same marker or to completely reconstruct a particular strain with a different marker, single-step exchange protocols of markers are a time-saving alternative. In recent years dominant drug resistance markers (DDRMs) against clonNAT, Hygromycin B, and Bleomycin have been adapted and successfully used in Schizosaccharomyces pombe. The corresponding DDRM cassettes - natMX, hphMX, and bleMX - all carry the $T E F$-promotor and -terminator sequences from Ashbya gossypii as kanMX, this provides flanking homologies to enable single-step marker swapping by homologous gene targeting. To expand this very useful toolset for single-step marker exchange I constructed $M X$-cassettes containing the nutritional markers $\arg 3^{+}$, his $^{+}$, leu1+, and ura4+. Furthermore, a set of constructs was created to enable single-step exchange of $u r a 4^{+}$ to kanMX6, natMX4, and hphMX4. The functionality of the cassettes is demonstrated by successful single-step marker swapping at several loci. These constructs allow a straight-forward and rapid remarking of existing $\mathrm{ura4}^{+-}$and $M X$-deleted and tagged strains.
\end{abstract}

Key words Schizosaccharomyces pombe, selectable marker, marker switch, plasmid, PCR

\section{Introduction}

As the field of molecular biology using the yeasts Saccharomyces cerevisiae and Schizosaccharomyces pombe as model organisms matured and moved into a postgenomic era, collections of strains with deletions or tagged versions of genes have been created. These collections originated either from a concerted effort to create genome-wide sets of gene deletions or tags [Hayashi et al. 2009; Kim et al. 2010; Spirek et al. 2010], or from the realization that availability of yeast strains beyond the lifetime of a particular research group would be hugely beneficial to the scientific community requiring long-term storage in bio-repositories such as the National BioResource Project (NBRP) of the MEXT, Japan

(http://yeast.lab.nig.ac.jp/nig/index en.html).

Historically, the most widely used selectable markers in Sz. pombe are the $\mathrm{ura}^{+}$gene and kanMX6, which confers resistance to the antibiotic G418 (geneticin) [Grimm et al. 1988; Bähler et al. 1998]; the $S$. cerevisiae $\mathrm{LEU2}^{+}$gene can rescue $\mathrm{Sz}$. pombe leu1 mutants when provided in multiple copies, which made it the ideal choice for a genetic marker on plasmid vectors [Beach and Nurse 1981; Maundrell 1993]. This rather small selection of markers is a potential hindrance when studying complex genetic interactions involving several factors and when investigating the subcellular localization of multiple proteins, or protein-protein interactions. To overcome this problem additional selectable markers have been introduced to $S z$. pombe, these include genes conferring resistance to the antibiotics clonNAT (nourseothricin), Hygromycin B, Bleomycin/Phleomycin, and Blasticidin S [Rabitsch et al. 2004; Sato et al. 2005; 
Hentges et al. 2005; Gregan et al. 2006; Erler et al. 2006]. The natMX (resistance against clonNAT), hphMX (resistance against Hygromycin B), and bleMX (resistance against Bleomycin/Phleomycin) constructs made use of the same promoter and terminator sequences from the TEF gene of the filamentous ascomycete Ashbya gossypii as the original kanMX cassette [Wach et al. 1994; Bähler et al. 1998; Goldstein and McCusker 1999; Sato et al. 2005; Hentges et al. 2005]. Especially, the natMX and $h p h M X$ (sometimes also referred to as hygMX) cassettes have been widely adopted to create multiply tagged and/or deleted strains [e.g., Rabitsch et al. 2004; Masuda et al. 2013; Ding and Forsburg 2014; Lorenz et al. 2014; Okada et al. 2014; Tsang et al. 2014]. The TEF sequences provide flanking homologies of a few 100 nucleotides which enable a simple single-step switching of selectable markers via targeted homologous integration [Sato et al. 2005; Hentges et al. 2005].

The constructs presented and validated here simplify the construction of multiply deleted and/or tagged fission yeast strains from already existing genetic modifications. This serves a different purpose than previously described 'marker switch' and 'knock-in' approaches for the targeted introduction of mutated open reading frames into wild-type cells [Maclver et al. 2003; Mudge et al. 2012; Fennessy et al. 2014]. The constructs described here offer new opportunities by enabling the direct exchange of $\mathrm{ura}^{+}$to DDRMs (dominant drug resistance markers) and of $M X$ type antibiotic markers to prototrophic markers in a simple, single-step transformation protocol.

\section{Materials and Methods}

\section{Enzymatic reactions for plasmid constructions and PCR amplification of DNA fragments for transformation}

PCR reactions for plasmid constructions were performed using either Phusion (Thermo Fisher Scientific Inc., Waltham, MA, USA) or Q5 (New England BioLabs Inc., Ipswich, MA, USA) highfidelity DNA polymerases. Oligonucleotides were supplied by Sigma-Aldrich Co. (St. Louis, MO, USA); and restriction endonucleases, and T4 DNA ligase were obtained from New England BioLabs Inc.. All relevant plasmid sections were verified by DNA sequencing.
The $\mathrm{ura}^{+}$marker swap cassettes were amplified from 100 ng of plasmid DNA (pALo120, pALo121, or pALo122) in a $50 \mu \mathrm{l}$ PCR reaction $(10 \mu \mathrm{l} 5 \times \mathrm{Q} 5$ Reaction Buffer, $200 \mu \mathrm{M}$ dNTPs, $500 \mathrm{nM}$ each of AL1forw and AL1rev oligonucleotides as primers, and $1 \mathrm{U}$ Q5 high-fidelity DNA polymerase) using the following PCR programme: $30 \mathrm{sec}$ at $98^{\circ} \mathrm{C}-35 \times(10$ sec at $98^{\circ} \mathrm{C}, 20 \mathrm{sec}$ at $55^{\circ} \mathrm{C}, 85 \mathrm{sec}$ at $\left.72^{\circ} \mathrm{C}\right)-120 \mathrm{sec}$ at $72^{\circ} \mathrm{C}$ (Figure 1B, Table 1). The $M X$ marker swap cassettes were amplified from $100 \mathrm{ng}$ of plasmid DNA (pFA6a-arg3MX4, pFA6a-his3MX4, pFA6aleu1MX4, or pFA6a-ura4MX4) in a $50 \mu \mathrm{l}$ PCR reaction $(10 \mu \mathrm{l} 5 \times$ Q5 Reaction Buffer, $200 \mu \mathrm{M}$ dNTPs, $500 \mathrm{nM}$ each of AL2forw and AL2rev oligonucleotides as primers, and $1 \mathrm{U}$ Q5 highfidelity DNA polymerase) using the following PCR programme: $30 \mathrm{sec}$ at $98^{\circ} \mathrm{C}-35 \times\left(10 \mathrm{sec}\right.$ at $98^{\circ} \mathrm{C}$, $20 \mathrm{sec}$ at $64^{\circ} \mathrm{C}, 90 \mathrm{sec}$ at $\left.72^{\circ} \mathrm{C}\right)-120 \mathrm{sec}$ at $72^{\circ} \mathrm{C}$ (Figure 2B, Table 1).

\section{Growth, media, and transformation}

For growing E. coli LB and SOC media - where appropriate containing $100 \mu \mathrm{g} / \mathrm{ml}$ Ampicillin were used [Sambrook and Russell 2000]. Competent cells from E. coli strains NEB5-alpha, NEB10-beta (New England BioLabs Inc.), Stellar (Clontech Laboratories Inc.), and XL1-blue (Agilent Technologies, Santa Clara, CA) were transformed following the protocols provided by the corresponding manufacturers.

Fission yeast strains used in this study are listed in Table 2. Schizosaccharomyces pombe cells were cultured on yeast extract (YE), and on yeast nitrogen base glutamate (YNG) agar plates containing the required supplements (concentration $250 \mu \mathrm{g} / \mathrm{ml}$ on $\mathrm{YE}$, and $75 \mu \mathrm{g} / \mathrm{ml}$ on YNG) [Sabatinos and Forsburg 2010; Smith 2009]. Concentrations for antibiotics used were: G-418 disulfate (ForMedium, Norfolk, UK) at $200 \mu \mathrm{g} / \mathrm{ml}$, clonNAT (Werner BioAgents, Jena, Germany) at 200 $\mu \mathrm{g} / \mathrm{ml}$, and Hygromycin B (ForMedium) at 400 $\mu \mathrm{g} / \mathrm{ml}$. All yeast transformations were performed using 1-5 $\mu \mathrm{g}$ of DNA in a standard Li-acetate protocol [Keeney and Boeke 1994], with the following modifications: (I) cells were grown in fully supplemented YE broth, (II) incubation of competent cells at $30^{\circ} \mathrm{C}$ was done for approximately 4 hours instead of 30-45 minutes, and (III) after the heat shock cells in transformation mix (40\% PEG in Li-acetate/TE) were immediately plated onto non-selective fully supplemented YE, and not pelleted and resuspended in water. The 
latter two modifications were suggested by Charles Hoffman (Boston College, Chestnut Hill, MA), and strongly improve transformation efficiency (http://listserver.ebi.ac.uk/pipermail/pombelist/2 014/004012.html). Yeast cells were grown for 1824 hours at $30^{\circ} \mathrm{C}$ on non-selective YE plates, and then replica-plated onto selective media; either fully supplemented YE agar containing an antibiotic (concentrations as above) or supplemented YNG agar lacking the appropriate amino acid or nucleobase.

\section{Obtaining the single-step marker switch cassettes}

Plasmids carrying the single-step marker switch cassettes described here will be available from the National BioResource Project (NBRP) of the MEXT, Japan

(http://yeast.lab.nig.ac.jp/nig/index en.html)

(Table 3). Plasmid sequences are available online as *.txt-files

http://dx.doi.org/10.6084/m9.figshare.1468419 [Lorenz 2015].

\section{Results and Disc ussion Construction of plasmids for marker switc hing ura4 to dominant drug resistance markers (DDRMs)}

A simple, high-copy vector with a single XbaI-site was created by PCR-amplifying pUC8 [Messing and Vieira 1982] using oligonucleotides AL3forw and AL3rev (Table 1). The resulting PCR product was digested with XbaI, treated with DpnI to remove pUC8 template DNA, and ligated using T4 DNA Ligase. This resulted in pUC8xba (Table 3), in which the entire multi-cloning site of pUC8 is replaced with a single Xbal-site. The $\mathrm{ura}^{+}{ }^{+}$marker [Grimm et al. 1988] was PCR-amplified from pREP42 [Basi et al. 1993] (oligonucleotides AL4forw and AL4rev; Table 1) exchanging the flanking HindIII-sites for XbaI-sites, this PCR product was then cloned into the XbaI-site of pUC8xba. The resulting plasmid was amplified using PCR (oligonucleotides AL5forw and AL5rev; Table 1) to give a fragment containing 5' and 3' ura4+-flanking sequences and the pUC8 vector backbone. This DNA fragment was then merged with a natMX4-cassette - released from pAG25 [Goldstein and McCusker 1999] by a PvuIISpeI digestion - using In-Fusion cloning (Clontech Laboratories Inc., CA, USA). Subsequently, the natMX4 marker was replaced by kanMX6- and
hphMX4-cassettes from pFA6a-kanMX6 [Bähler et al. 1998] and pAG32 [Goldstein and McCusker 1999], respectively, by standard cloning using BglII- and EcoRV-sites. The resulting plasmids pALo120 (kanMX6), pALo121 (natMX4), and pAlo122 (hphMX4) (Table 3) carry $\sim 220$ bp of the $5^{\prime}$ and $3^{\prime}$ ends of the $1.8 \mathrm{~kb}$-fragment of $\mathrm{ura}^{+}$ [Grimm et al. 1988]. These ura $^{+}$-marker switch cassettes can be liberated by a XbaI restriction digest or PCR using oligonucleotides AL1 forw and AL1rev (Figure 1, Table 1). The $\mathrm{ura}^{+}$gene at its original locus in strain UoA66 was knocked out using PCR products, AL1forw-AL1rev on pALo120, pALo121, and pALo122 (as described above). Correct integration was monitored by testing for an antibiotic-resistant Ura phenotype, and frequencies of correct integration between 22.9\% and $37.1 \%$ were observed (Table 4). Furthermore, three independent $\mathrm{ura}^{+}$-marked constructs $\mathrm{pms}^{-}$

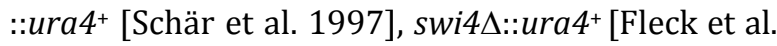
1992], and meu13s::ura4+ [Nabeshima et al. 2001] were efficiently replaced with the clonNAT (XbaIdigest of pALo121) or Hygromycin B (XbaI-digest of pALo122) resistance gene. Frequencies of correct integration for pms1::ura4 ${ }^{+}$to pms1-16::natMX4

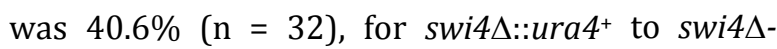
36::hphMX4 was $100 \% \quad(\mathrm{n}=6)$, and for

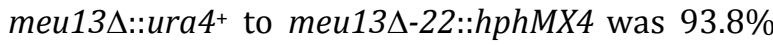
$(n=32)$. In these instances correct integration was not only tested by an antibiotic-resistant Uraphenotype, but also verified by colony PCR on a few selected transformants (data not shown). A slightly different construct with larger ura4$^{+}$-flanking homologies was successfully used to swap a

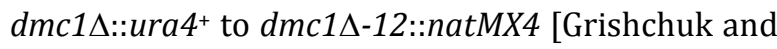
Kohli 2003; Lorenz et al. 2012]. Frequencies of correct integration are similar to what was reported previously for fission yeast [Bähler et al. 1998; Sato et al. 2005].

\section{Construction of plasmids for targeting the ura 4 open reading frame}

The ura4 gene represents a negatively and positively selectable marker; ura $^{+}$cells can grow on minimal media lacking uracil, but are killed by 5FOA (5-fluoroorotic acid) treatment [Boeke et al. 1984; Grimm et al. 1988]. To fully exploit the dual selection feature of the ura4 marker, plasmids solely carrying the ura4-targeting sequences were also constructed. 5' phosphorylated oligonucleotides AL6forw and AL6rev (Table 1) were used to perform PCR on pALo120. The 
resulting PCR product was ligated with T4 DNA ligase after DpnI treatment to remove pALo120 template DNA to give pALo125. This plasmid can be used to remove $\mathrm{ura}^{+}$for marker recycling, although it should be kept in mind, that this will leave a $440 \mathrm{bp}$ scar which still can be targeted by the $1.8 \mathrm{~kb}$ ura $4^{+}$-fragment [Grimm et al. 1988]. In principle, this is not an issue for constructing multiply deleted or tagged strains with these cassettes, because the initial marker swap will be performed in a background with a single deletion or tag, subsequently differently marked mutants and tags will be combined by crossing.

In order to enable delivering potentially any construct or open reading frame to the ura 4 locus, pALo120 was amplified by PCR using oligonucleotides AL7forw and AL7rev (Table 1). The resulting PCR product was digested with BgIII and DpnI, and ligated using T4 DNA ligase, this created a plasmid (pALo126; Table 3) with a large multicloning site (HindIII - BsiWI - PstI - SalI BamHI - SmaI - PacI - BssHII - BglII - SacI - EcoRI - BspDI - EcoRV - SpeI) flanked by the two $\sim 220 \mathrm{bp}$ ura4-targeting sequences. The ura $^{+}$targeting cassettes can be released from pALo125 or pALo126, respectively, by a XbaI restriction digest or amplified by PCR using oligonucleotides AL1forw and AL1rev (Table 1).

\section{Construction of arg3MX4, his3MX4, leu1MX4, and ura 4MX4 plasmids}

To enable marker switching between any DDRM flanked by TEF-promotor and -terminator sequences present in all the $M X$ constructs - and the prototrophic markers $\arg 3^{+}$, his $3^{+}$, leu $1^{+}$, and ura4+ $4^{+}$pAG25 was amplified using oligonucleotides AL8forw and AL8rev (Table 1). The resulting PCR product was digested with NheI and DpnI, and ligated using T4 DNA ligase. This created pALo123 (Table 3), which carries the TEF-promotor and terminator sequences with an intervening NheI site. The $\arg 3^{+}$open reading frame [Waddell and Jenkins 1995] including its own promoter and terminator was amplified by PCR with oligonucleotides AL9forw and AL9rev (Table 1) using genomic DNA from UoA474 as a template, the PCR product was digested with XbaI and cloned into the compatible NheI site of pALo123 resulting in pFA6a-arg3MX4 (Table 3). The his3+ marker was amplified by PCR from pFOX2 [Osman et al. 2000] using oligonucleotides AL10forw and AL10rev (Table 1) replacing the original BglII sites with
NheI sites. The resulting PCR product was cloned into the Nhel site of pALo123, which resulted in pFA6a-his3MX4 (Table 3). A functional leu1+ open reading frame [Kikuchi et al. 1988] including its own promoter and terminator was amplified by PCR using oligonucleotides AL11forw and AL11rev (Table 1) and genomic DNA from UoA474 as a template. The PCR product was digested with XbaI and cloned into the compatible Nhel-site of pALo123 to give pFA6a-leu1MX4 (Table 3). Finally, the $\mathrm{ura}^{+}$marker was cloned as an Xbal fragment (see above) into the compatible NheI site of pALo123 to give pFA6a-ura4MX4 (Table 3). Prototrophic markers are transcribed using their respective original promoters and terminators, $P_{T E F^{-}}$and $T_{T E F^{-}}$-Sequences just provide flanking homology for gene targeting in these constructs.

To perform marker switching with the resulting prototrophic $M X$ cassettes, they can be amplified by PCR using oligonucleotides AL2forw and AL2rev (Figure 2, Table 1). Alternatively, they can also be released by a BamHI-EcoRI double restriction digest, except for his3MX4 which requires a BglIISacI restriction digest. The $\arg 3 M X 4$, his $3 M X 4$, leu1MX4, and ura4MX4 cassettes were amplified by PCR (as above) from their respective plasmids and transformed into the UoA193 strain, which has the hop1 gene knocked-out with kanMX6. hop1 codes for a meiosis-specific chromosome axis protein [Lorenz et al. 2004; Lorenz et al. 2006]. Meiosisspecific factors seem to be more refractory to correct targeting than genes coding for non-meiotic proteins [Bähler et al. 1998], therefore the hop1 locus presents an optimal target to test the efficiency limits of one-step marker swapping. Frequencies of correct integration ranging from $15.3 \%$ to $36.6 \%$ (Table 4 ) were observed by monitoring for $\mathrm{Arg}^{+} \mathrm{G} 418$-sensitive, $\mathrm{His}^{+} \mathrm{G} 418$ sensitive, $\mathrm{Leu}^{+} \mathrm{G} 418$-sensitive, and $\mathrm{Ura}^{+} \mathrm{G} 418$ sensitive phenotypes.

\section{Conclusion}

Here, 7 new constructs for single-step marker replacement are reported and tested for functionality. Three of these will be useful tools for the fission yeast community to swap deletions and tagged versions of open reading frames from the widely-used $\mathrm{ura}^{+}$marker to 3 antibiotic markers (a.k.a. DDRMs) conferring resistance to G418, clonNAT, or Hygromycin B, respectively. The other 4 can be used to exchange any $M X$-type marker 
(flanked by $P_{T E F^{-}}$and $T_{T E F^{-}}$sequences) for the $S z$. pombe genes encoding the prototrophic markers Ura4, Arg3, His3, or Leu1. These marker swap cassettes will simplify the construction of strains deleted and/or tagged at multiple loci.

Acknowledgements This work was funded by a start-up grant from the College of Life Science and Medicine, University of Aberdeen, UK. I am grateful to J. Bähler, E. Hartsuiker, F. Klein, J. Kohli, K. Nasmyth, M. C. Whitby, the Leibniz Institute - German Collection of Microorganisms and Cell Cultures (DMSZ) and the National BioResource Project Japan (NBRP) for providing materials used in this study. I thank Alistair J. P. Brown and Takashi Kubota for critically reading this manuscript.

\section{References}

Bähler J, Wu JQ, Longtine MS, Shah NG, McKenzie A, Steever AB, Wach A, Philippsen P, Pringle JR. 1998. Heterologous modules for efficient and versatile PCR-based gene targeting in Schizosaccharomyces pombe. Yeast, 14: 943-51.

Basi G, Schmid E, Maundrell K. 1993. TATA box mutations in the Schizosaccharomyces pombe nmt1 promoter affect transcription efficiency but not the transcription start point or thiamine repressibility. Gene, 123: 131-6.

Beach D, Nurse P. 1981. High-frequency transformation of the fission yeast Schizosaccharomyces pombe. Nature, 290: 140-2.

Boeke JD, LaCroute F, Fink GR. 1984. A positive selection for mutants lacking orotidine-5'-phosphate decarboxylase activity in yeast: 5 -fluoro-orotic acid resistance. Mol. Gen. Genet., 197: 345-6.

Ding L, Forsburg SL. 2014. Essential domains of Schizosaccharomyces pombe Rad8 required for DNA damage response. G3 (Bethesda), 4: 13731384.

Erler A, Maresca M, Fu J, Stewart AF. 2006. Recombineering reagents for improved inducible expression and selection marker re-use in Schizosaccharomyces pombe. Yeast, 23: 813-23.

Fennessy D et al. 2014. Extending the Schizosaccharomyces pombe molecular genetic toolbox. PLoS One, 9: e97683.

Fleck O, Michael H, Heim L. 1992. The swi4+ gene of Schizosaccharomyces pombe encodes a homologue of mismatch repair enzymes. Nucleic Acids Res., 20: 2271-2278.

Goldstein AL, McCusker JH. 1999. Three new dominant drug resistance cassettes for gene disruption in Saccharomyces cerevisiae. Yeast, 15: 1541-53.

Gregan J, Rabitsch PK, Rumpf C, Novatchkova M, Schleiffer A, Nasmyth K. 2006. High-throughput knockout screen in fission yeast. Nat. Protoc., 1: 2457-2464.

Grimm C, Kohli J, Murray J, Maundrell K. 1988. Genetic engineering of Schizosaccharomyces pombe: a system for gene disruption and replacement using the ura4 gene as a selectable marker. Mol. Gen. Genet., 215: 81-6.

Grishchuk AL, Kohli J. 2003. Five RecA-like proteins of Schizosaccharomyces pombe are involved in meiotic recombination. Genetics, 165: 1031-43.

Hayashi A, Ding D-Q, Da-Qiao D, Tsutsumi C, Chikashige Y, Masuda H, Haraguchi T, Hiraoka Y. 2009. Localization of gene products using a chromosomally tagged GFP-fusion library in the fission yeast Schizosaccharomyces pombe. Genes Cells, 14: 217-25.

Hentges P, Van Driessche B, Tafforeau L, Vandenhaute J, Carr AM. 2005. Three novel antibiotic marker cassettes for gene disruption and marker switching in Schizosaccharomyces pombe. Yeast, 22: 1013-9.

Keeney JB, Boeke JD. 1994. Efficient targeted integration at leu1-32 and ura4-294 in Schizosaccharomyces pombe. Genetics, 136: 849-56.

Kikuchi Y, Kitazawa Y, Shimatake H, Yamamoto M. 1988. The primary structure of the leu1+ gene of Schizosaccharomyces pombe. Curr. Genet., 14: 3759.

Kim D-U et al. 2010. Analysis of a genome-wide set of gene deletions in the fission yeast Schizosaccharomyces pombe. Nat. Biotechnol., 28: 617-623.

Lorenz A. 2015. Plasmid sequences - New cassettes for single-step drug-resistance and prototrophic marker switching in fission yeast. figshare. http://dx.doi.org/10.6084/m9.figshare.1468419.

Lorenz A, Estreicher A, Kohli J, Loidl J. 2006. Meiotic recombination proteins localize to linear elements in Schizosaccharomyces pombe. Chromosoma, 115: 330-40.

Lorenz A, Mehats A, Osman F, Whitby MC. 2014. Rad51/Dmc1 paralogs and mediators oppose DNA helicases to limit hybrid DNA formation and promote crossovers during meiotic recombination. Nucleic Acids Res., 42: 13723-13735.

Lorenz A, Osman F, Sun W, Nandi S, Steinacher R, Whitby MC. 2012. The fission yeast FANCM ortholog directs non-crossover recombination during meiosis. Science, 336: 1585-8.

Lorenz A, Wells JL, Pryce DW, Novatchkova M, Eisenhaber F, McFarlane RJ, Loidl J. 2004. S. pombe meiotic linear elements contain proteins related to synaptonemal complex components. J. Cell Sci., 117: 3343-51.

MacIver FH, Glover DM, Hagan IM. 2003. A "marker switch" approach for targeted mutagenesis of genes in Schizosaccharomyces pombe. Yeast, 20: 587-94.

Masuda H, Mori R, Yukawa M, Toda T. 2013. Fission yeast MOZART1/Mzt1 is an essential $\gamma$-tubulin complex component required for complex recruitment to the microtubule organizing center, but not its assembly. Mol. Biol. Cell, 24: 2894-906. 
Maundrell K. 1993. Thiamine-repressible expression vectors pREP and pRIP for fission yeast. Gene, 123: 127-30.

Messing J, Vieira J. 1982. A new pair of M13 vectors for selecting either DNA strand of double-digest restriction fragments. Gene, 19: 269-276.

Mudge DK, Hoffman CA, Lubinski TJ, Hoffman CS. 2012. Use of a ura5+-lys7+ cassette to construct unmarked gene knock-ins in Schizosaccharomyces pombe. Curr. Genet., 58: 59-64.

Nabeshima K, Kakihara Y, Hiraoka Y, Nojima H. 2001. A novel meiosis-specific protein of fission yeast, Meu13p, promotes homologous pairing independently of homologous recombination. EMBO J., 20: 3871-81.

Okada N, Toda T, Yamamoto M, Sato M. 2014. CDKdependent phosphorylation of Alp7-Alp14 (TACCTOG) promotes its nuclear accumulation and spindle microtubule assembly. Mol. Biol. Cell, 25: 1969-82.

Osman F, Adriance M, McCready S. 2000. The genetic control of spontaneous and UV-induced mitotic intrachromosomal recombination in the fission yeast Schizosaccharomyces pombe. Curr. Genet., $\mathbf{3 8}$ : 113-25.

Rabitsch KP, Javerzat J-P, Gregan J, Schleiffer A, Eisenhaber F, Nasmyth K. 2004. Two fission yeast homologs of Drosophila Mei-S332 are required for chromosome segregation during meiosis I and II. Curr. Biol., 14: 287-301.
Sabatinos SA, Forsburg SL. 2010. Molecular genetics of Schizosaccharomyces pombe. Methods Enzymol., 470: 759-95.

Sambrook JF, Russell DW. 2000. Molecular Cloning: A Laboratory Manual. 3rd ed. Cold Spring Harbor Laboratory Press: Cold Spring Harbor.

Sato M, Dhut S, Toda T. 2005. New drug-resistant cassettes for gene disruption and epitope tagging in Schizosaccharomyces pombe. Yeast, 22: 583-91.

Schär P, Baur M, Schneider C, Kohli J. 1997. Mismatch repair in Schizosaccharomyces pombe requires the mutL homologous gene pms1: molecular cloning and functional analysis. Genetics, 146: 1275-86.

Smith GR. 2009. Genetic analysis of meiotic recombination in Schizosaccharomyces pombe. Methods Mol. Biol., 557: 65-76.

Spirek M et al. 2010. S. pombe genome deletion project: An update. Cell Cycle, 9: 2399-2402.

Tsang E, Miyabe I, Iraqui I, Zheng J, Lambert S a E, Carr AM. 2014. The extent of error-prone replication restart by homologous recombination is controlled by Exo1 and checkpoint proteins. J. Cell Sci., 127: 2983-94.

Wach A, Brachat A, Pöhlmann R, Philippsen P. 1994. New heterologous modules for classical or PCR-based gene disruptions in Saccharomyces cerevisiae. Yeast, 10: 1793-1808.

Waddell S, Jenkins JR. 1995. arg3+, a new selection marker system for Schizosaccharomyces pombe: application of ura4+ as a removable integration marker. Nucleic Acids Res., 23: 1836-7.

Table 1. List of oligonucleotides used

\begin{tabular}{ll}
\hline Oligonucleotide No. & Oligo (in 5' $\rightarrow 3^{\prime}$ direction) \\
\hline AL1forw & agctacaaatccactgg \\
AL1rev & gtgatattgacgaaactttttg \\
AL2forw & gtttagcttgcctcgtccc \\
AL2rev & gatggcggcgttagtatcg \\
AL3forw & aattaaTCTAGAcgtaatcatggtcatagctgtttcc \\
AL3rev & aattaaTCTAGAggcactggccgtcgttttac \\
AL4forw & ctctTCTAGAagctacaaatcccac \\
AL4rev & ctctTCTAGAgtgatattgacgaaac \\
AL5forw & GATGATATCAGATCCACTAGTcatgctcctacaacattacc \\
AL5rev & AGCGTACGAAGCTTCAGCTGgctgattatctttttcaccatgc \\
AL6forw & [phos]gctgattatctttttcaccatgc \\
AL6rev & [phos]catgctcctacaacattacc \\
AL7forw & gggacgaggcaagctaaac \\
AL7rev & aattaaAGATCTgagctcgaattcatcgatg \\
AL8forw & aattaaGCTAGCcatggttgtttatgttcg \\
AL8rev & aattaaGCTAGCcctaatcagtactgac \\
AL9forw & aattaaTCTAGAcgtactagcttgtttgc \\
AL9rev & aattaaTCTAGAggaagacaagaaaaagcc \\
AL10forw & aattaaGCTAGCtctatgcaaagctaacgaatc \\
AL10rev & aattaaGCTAGCtttcaacgttttctttactattgc \\
AL11forw & aattaaTCTAGAtcgatatcccaatctgtag \\
AL11rev & aattaaTCTAGAttatgttacaggttacttcg \\
\hline & \\
\end{tabular}


Table 2. Yeast strain list

\begin{tabular}{|c|c|c|}
\hline Strain & Relevant genotype & Origin \\
\hline UoA66 & $h^{\text {-smto }}$ arg3-D4 his3-D1 leu1-32 & lab strain \\
\hline PRS301a & $h^{-}$pms1-::ura4+ ura4-D18 & [Schär et al. 1997] \\
\hline UoA372 & $h^{+S}$ pms1-:ura4+ arg3-D4 his3-D1 leu1-32 ura4-D18 & this studyb \\
\hline UoA386 & $h^{+S}$ pms1-16::natMX4 arg3-D4 his3-D1 leu1-32 ura4-D18 & this study \\
\hline OL278c & $h^{+}$swi4 $::$ura $^{+}$ade6-M387 ura4-D18d & [Fleck et al. 1992] \\
\hline UoA375 & $h^{-s m t 0}$ swi44::ura $4^{+}$arg3-D4 his3-D1 leu1-32 ura4-D18d & this studye \\
\hline UoA389 & $h^{-s m t 0}$ swi4-36::hphMX4 arg3-D4 his3-D1 leu1-32 ura4-D18d & this study \\
\hline $118-4682^{\mathrm{f}}$ & h- meu13s::ura4+ ade6-M210 leu1-32 ura4-D18 & [Nabeshima et al. 2001] \\
\hline UoA581 & 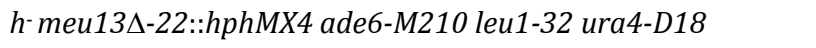 & this study \\
\hline UoA474 & $h$ - ade6-149 & lab strain \\
\hline UoA193 & h- hop1-1::kanMX6 arg3-D4 his3-D1 leu1-32 ura4-D18 & lab strain \\
\hline
\end{tabular}

aprovided as FY18790 by the National BioResource Project (NBRP) of the MEXT, Japan.

bDerivative of PRS301.

cprovided as FY18812 by the National BioResource Project (NBRP) of the MEXT, Japan.

dThe original construct as described by Fleck and coworkers [Fleck et al. 1992] also partially deletes the neighbouring open reading frame $d p h 3$, so these strains in effect are swi $4 \Delta d p h 3 \Delta$ double mutants.

eDerivative of OL278.

fprovided by Jürg Kohli.

Table 3. List of plasmids created in this study

\begin{tabular}{|c|c|c|c|}
\hline Plasmid & FYP number & Insert & Purpose \\
\hline pALo120 & 2884 & $\begin{array}{l}\text { ura4 5' flanking sequence - kanMX6 - ura4 3' } \\
\text { flanking sequence }\end{array}$ & $\begin{array}{l}\text { ura4 } 4^{+} \text {to kanMX6 marker } \\
\text { swap }\end{array}$ \\
\hline pALo121 & 2885 & $\begin{array}{l}\text { ura } 45^{\prime} \text { flanking sequence - natMX4 - ura } 4 \text { 3' } \\
\text { flanking sequence }\end{array}$ & $\begin{array}{l}\text { ura } 4^{+} \text {to natMX4 marker } \\
\text { swap }\end{array}$ \\
\hline pALo122 & 2886 & $\begin{array}{l}\text { ura } 45^{\prime} \text { flanking sequence - hphMX4 - ura4 3' } \\
\text { flanking sequence }\end{array}$ & $\begin{array}{l}\text { ura } 4^{+} \text {to } h p h M X 4 \text { marker } \\
\text { swap }\end{array}$ \\
\hline pALo123 & 2887 & $P_{T E F}-$ NheI $-T_{T E F}$ & $M X$ targeting \\
\hline pALo125 & 2888 & $\begin{array}{l}\text { ura } 4 \text { 5' flanking sequence - } \\
\text { ura4 3' flanking sequence }\end{array}$ & $\begin{array}{l}\text { ura } 4^{+} \text {deletion/marker } \\
\text { recycling }\end{array}$ \\
\hline pALo126 & 2889 & $\begin{array}{l}\text { ura4 5' flanking sequence - MCS - } \\
\text { ura4 3' flanking sequence }\end{array}$ & ura $4^{+}$targeting \\
\hline pFA6a-arg3MX4 & 2890 & $P_{T E F}-\arg 3^{+}-T_{T E F}$ & $M X$ to $\arg 3^{+}$marker swap \\
\hline pFA6a-his3MX4 & 2891 & $P_{T E F}-h i s 3^{+}-T_{T E F}$ & $M X$ to his3 ${ }^{+}$marker swap \\
\hline pFA6a-leu1MX4 & 2892 & $P_{T E F}-l e u 1^{+}-T_{T E F}$ & $M X$ to leu1+ marker swap \\
\hline pFA6a-ura4MX4 & 2893 & $P_{T E F}-u r a 4^{+}-T_{T E F}$ & $M X$ to ura $^{+}{ }^{+}$marker swap \\
\hline pUC8xba & 2894 & none & general cloning \\
\hline
\end{tabular}

arefer to FYP numbers when obtaining plasmids from the National BioResource Project (NBRP) of the MEXT, Japan.

Table 4. Efficiency of correct integration during marker swap

\begin{tabular}{ccccc}
\hline Strain transformed & Original Marker/Gene & New Marker & Positives/Total & \% correct integration \\
\hline UoA66 & ura4 $^{+}$ & kanMX6 & $8 / 35$ & $22.9 \%$ \\
UoA66 & ura4 $^{+}$ & natMX4 & $13 / 35$ & $37.1 \%$ \\
UoA66 & ura4 $^{+}$ & hphMX4 & $8 / 35$ & $22.9 \%$ \\
UoA193 & kanMX6 & arg3 $^{+}$ & $23 / 69$ & $33.3 \%$ \\
UoA193 & kanMX6 & his3 $^{+}$ & $11 / 72$ & $15.3 \%$ \\
UoA193 & kanMX6 & leu1 & $16 / 70$ & $22.9 \%$ \\
UoA193 & kanMX6 & ura4 & $36.6 \%$ \\
\hline
\end{tabular}


A

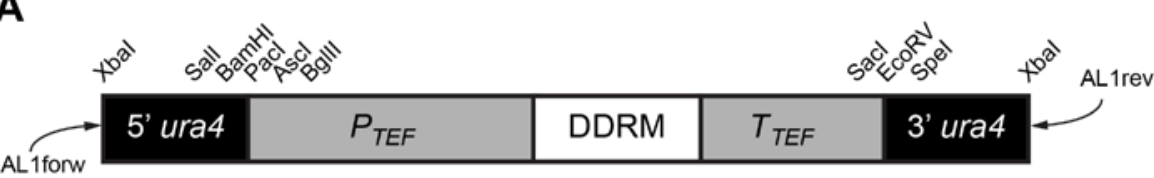

B

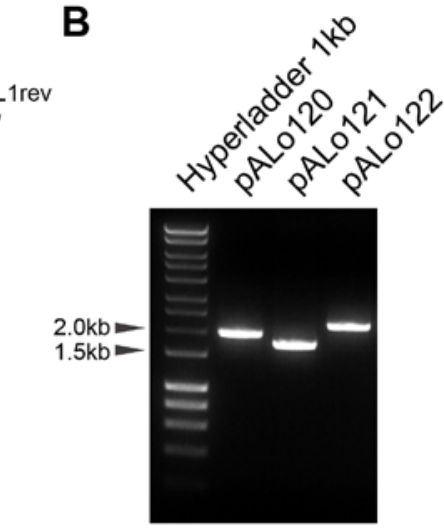

pAL0122

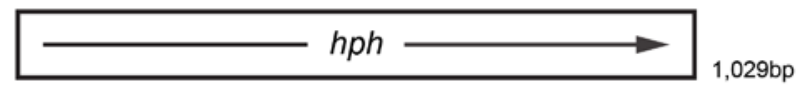

Figure 1. ura4+ to dominant drug resistance marker (DDRM) swap cassettes. (A) Schematic representation of the structure of the ura4+ gene to DDRM swap cassettes on the corresponding plasmids (pALo120, pALo121, pALo122). Size of the DDRM gene in bp is indicated. The direction of transcription is shown as arrows within the box representing the marker, DDRMs are driven by the TEF-promoter $\left(P_{T E F}\right)$ and terminated at the $T E F$-terminator $\left(T_{T E F}\right)$. The positions of the Xbal sites for cassette release are indicated, as are restriction sites unique in all 3 constructs, for further restriction sites consult the corresponding sequence files. (B) Amplifying ura $4^{+}$to DDRM swap cassettes. DNA molecular weight marker in $1^{\text {st }}$ lane is Hyperladder $1 \mathrm{~kb}$ (Bioline, London, UK) $(4 \mu \mathrm{l})$. Bands are $2 \mu \mathrm{l}$ of a $50 \mu \mathrm{l}$ PCR reaction as described in Materials and Methods. Expected band size for each PCR product as follows: pALo120 $(1,973$ bp), pALo121 (1,739 bp), and pALo122 (2,195 bp). DNA was loaded onto a 0.8\% Agarose (Bioline) gel (1× TAE) containing $0.5 \mu \mathrm{g} / \mathrm{ml}$ ethidium bromide (Sigma-Aldrich Co.).

A

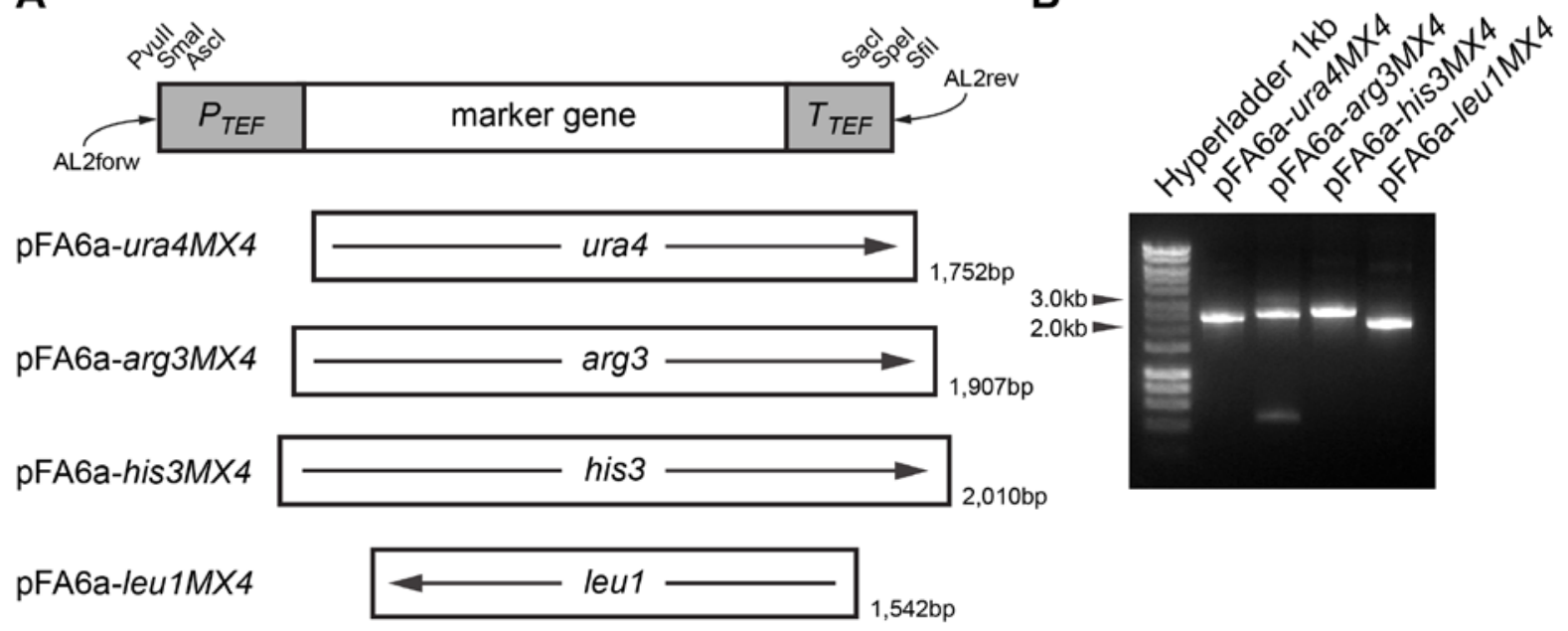

Figure 2. $M X$ to prototrophic marker swap cassettes. (A) Schematic representation of the structure of the $M X$ to prototrophic marker swap cassettes on the corresponding plasmids (pFA6a-ura4MX4, pFA6a-arg3MX4, pFA6ahis3MX4, pFA6a-leu1MX4). Size of the corresponding gene in bp is indicated. The direction of transcription is shown as arrows within the box representing the marker, prototrophic markers are transcribed using their respective original promoters and terminators, $P_{T E F}$-and $T_{T E F}$-sequences just provide flanking homology for gene targeting in these constructs. Restriction sites unique in all 3 constructs are given, for further restriction sites consult the corresponding sequence files. (B) Amplifying $M X$ marker swap cassettes. DNA molecular weight marker in $1^{\text {st }}$ lane is Hyperladder $1 \mathrm{~kb}$ (Bioline) $(4 \mu \mathrm{l})$. Bands are $2 \mu \mathrm{l}$ of a $50 \mu \mathrm{l}$ PCR reaction as described in Materials and Methods. Expected band size for each PCR product as follows: pFA6a-ura4MX4 (2,387 bp), pFA6a-arg3MX4 (2,540 bp), pFA6a-his3MX4 (2,645 bp), and pFA6a-leu1MX4 (2,185 bp). DNA was loaded onto a 0.8\% Agarose (Bioline) gel (1× TAE) containing $0.5 \mu \mathrm{g} / \mathrm{ml}$ ethidium bromide (Sigma-Aldrich Co.). 